\title{
Stromal Expression of Activated Leukocyte Cell Adhesion Molecule Promotes Lung Tumor Growth and Metastasis
}

Ann-Helen Willrodt, ${ }^{*}$ Michal Beffinger, ${ }^{\dagger}$ Martina Vranova, ${ }^{*}$ Darya Protsyuk, ${ }^{\ddagger}$ Katja Schuler, ${ }^{*}$ Maria Jadhav, ${ }^{*}$ Mathias Heikenwalder, ${ }^{\S}$ Maries van den Broek, ${ }^{\dagger}$ Lubor Borsig, ${ }^{\ddagger}$ and Cornelia Halin*

From the Institute of Pharmaceutical Sciences, * ETH Zurich (Swiss Federal Institute of Technology), Zurich, Switzerland; the Institutes of Experimental Immunology ${ }^{\dagger}$ and Physiology, ${ }^{\ddagger}$ University of Zurich, Zurich, Switzerland; and the Division of Chronic Inflammation and Cancer, ${ }^{\S}$ German Cancer Research Center, Heidelberg, Germany

Accepted for publication July 26, 2017.

Address correspondence to Cornelia Halin, Ph.D., Institute of Pharmaceutical Sciences, ETH Zurich, Wolfgang-Pauli Str. 10, CH-8093 Zurich, Switzerland. E-mail: cornelia. halin@pharma.ethz.ch.

\begin{abstract}
Activated leukocyte cell adhesion molecule (ALCAM) is expressed on various cell types, including leukocytes, endothelial cells, and certain tumor cells. Although ALCAM expression on tumor cells has been linked to tumor invasion and metastatic spread, the contribution of ALCAM expressed in cells forming the tumor stroma to cancer progression has not been investigated. In this study, ALCAM-deficient ( $\left.\mathrm{ALCAM}^{-/}\right)$mice were used to evaluate the role of ALCAM in lung tumor growth and metastasis. $\mathrm{ALCAM}^{-/-}$mice displayed an altered blood vascular network in the lung and the diaphragm, indicative of an angiogenetic defect. The absence of ALCAM expression in cells forming the stromal tumor microenvironment profoundly affected lung tumor growth in three different i.v. metastasis models. In the case of Lewis lung carcinoma (LLC), an additional defect in tumor cell homing to the lungs and a resulting reduction in the number of lung tumor nodules were observed. Similarly, when LLC cells were implanted subcutaneously for the study of spontaneous tumor cell metastasis, the rate of LLC metastasis to the lungs was profoundly reduced in $\mathrm{ALCAM}^{-1}$ mice. Taken together, our work demonstrates for the first time the in vivo contribution of ALCAM to angiogenesis and reveals a novel role of stromally expressed ALCAM in supporting tumor growth and metastatic spread. (Am J Pathol 2017, 187: 2558-2569; http://dx.doi.org/10.1016/j.ajpath.2017.07.008)
\end{abstract}

Cell adhesion molecules (CAMs) are transmembrane proteins that are involved in cell-cell and cell-extracellular matrix interactions. Many studies have documented the involvement of CAMs in various steps of tumor progression and metastatic spread, namely in tumor cell interaction with the extracellular matrix, invasion, expansion of the intraand peritumoral vasculature, entry and exit of tumor cells from the circulation, and finally metastatic outgrowth in distant organs. ${ }^{1,2}$ In addition, CAMs are crucial for the recruitment and activation of leukocytes during an antitumor immune response. ${ }^{3}$ Activated leukocyte CAM (ALCAM; CD166) is a member of the immunoglobulin superfamily and has been implicated in many of the above-mentioned processes. ALCAM engages in homophilic, as well as heterophilic, interactions with its binding partners CD6, galectin 8, and L1CAM. ${ }^{4-6}$ ALCAM expression by $\mathrm{T}^{-}$cells ${ }^{7}$ and monocytes ${ }^{8}$ has been shown to mediate the migration of leukocytes across ALCAM-expressing endothelial cell monolayers, whereas the interaction of ALCAM expressed on dendritic cells with CD6 expressed on T cells reportedly contributes to T-cell activation in vitro. ${ }^{9,10}$ In addition, ALCAM expressed by vascular endothelial cells has been shown to support angiogenic processes in vitro. ${ }^{11,12}$ Although the expression of ALCAM in blood vessels in vivo has been demonstrated in the human and murine central nervous systems, ${ }^{7,13}$ the human skin, ${ }^{11}$ the rat lung, ${ }^{14}$ and the murine liver ${ }^{15}$ and lung, ${ }^{11}$ its in vivo contribution to angiogenesis has not been investigated to

Supported by Swiss National Science Foundation grants 310030_138330 and 310030_156269, the Promedica Foundation, and ETH Zurich (Swiss Federal Institute of Technology), Zurich, Switzerland (C.H.).

M.B. and M.V. contributed equally to this work.

Disclosures: None declared. 
date. In this context, our group recently described the expression of ALCAM in lymphatic endothelial cells and its involvement in the formation of lymphatic vessels, thereby providing the first in vivo evidence of the relevance of ALCAM in endothelial cell biology. ${ }^{11}$ Moreover, a recent study reported the role of ALCAM in regulating the expression of tight-junction proteins and controlling vascular permeability of the blood-brain barrier. ${ }^{13}$

In addition to leukocytes and endothelial cells, several other cells, such as neurons, ${ }^{16}$ certain epithelial cells, ${ }^{17}$ and keratinocytes, ${ }^{18}$ reportedly express ALCAM. Moreover, ALCAM expression by cancer cells has been linked to the grades of tumor malignancy, apoptotic resistance, epithelial-mesenchymal transition, and patient prognosis. ${ }^{3}$ For example, in gastric cancer, ${ }^{19}$ colorectal cancer, ${ }^{20,21}$ pancreatic cancer, ${ }^{22}$ prostate cancer, ${ }^{23,24}$ or melanoma,,${ }^{25-27}$ ALCAM expression has been shown to positively correlate with cancer progression. The tumor stroma, which consists of cells forming the tumor vasculature, immune cells, fibroblasts, and the extracellular matrix, is known to directly affect tumor cell survival, tumor growth, and progression. ${ }^{28-30}$ However, the contribution of stromal ALCAM to in vivo tumor growth has not been examined. In this study, we compared lung tumor growth and metastatic spread in $\mathrm{ALCAM}^{-1-}$ mice to those in wild-type (WT) mice. Performing experiments in three different i.v. lung metastasis models, we show that the absence of ALCAM expression in stromal cells markedly reduced metastatic outgrowth in the lungs of $\mathrm{ALCAM}^{-1-}$ compared to WT mice. The tumor growth retardation was associated with an angiogenetic defect and-in the case of Lewis lung carcinoma (LLC) with reduced ability of tumor cells to home to the lungs in $\mathrm{ALCAM}^{-1-}$ mice. In summary, our work reveals a novel contribution of ALCAM expressed by cells forming the stromal tumor microenvironment to metastatic spread and tumor outgrowth in the lung.

\section{Materials and Methods}

\section{Mice}

WT C57BL/6-J mice (Janvier, Genest-Saint-Isle, France) and $\mathrm{ALCAM}^{-/-}$mice ${ }^{16}$ obtained from The Jackson Laboratory (Bar Harbor, ME) were housed in the animal facility of ETH Zurich (Swiss Federal Institute of Technology) or of the University of Zurich (Zurich, Switzerland). All experiments were approved by the Cantonal Veterinary Office (Zurich, Switzerland).

\section{Cell Lines}

The melanoma cell line B16F10 (Caliper, Hopkinton, MA) transfected with luciferase (B16F10-luc2) was kindly provided by Dr. Michael Detmar, ETH Zurich. Cells were cultured in Dulbecco's modified Eagle's medium (InvitroGen, Carlsbad, CA) supplemented with $10 \%$ fetal calf serum (Life Technologies, Carlsbad, CA) and 1\% antibiotic-antimycotic (Life Technologies). The colon adenocarcinoma cell line MC38 Green fluorescent protein, ${ }^{31}$ the LLC cell line ${ }^{32}$ (ATCC, Manassas, VA) as well as LLCs lentivirally transfected with luciferase, were cultured as previously described. ${ }^{33}$ Human umbilical vein endothelial cells (HUVECs; PromoCell, Heidelberg, Germany) were cultured on plates coated with $10 \mu \mathrm{g} / \mathrm{mL}$ collagen type I (Advanced BioMatrix, Poway, CA) and 10 $\mu \mathrm{g} / \mathrm{mL}$ fibronectin (Merck, Darmstadt, Germany) in Endothelial Cell Growth Medium 2-Microvascular without vascular endothelial growth factor A (Lonza, Basel, Switzerland). Mouse Mile Sven (MS)-1 cells $^{34}$ were cultured in Dulbecco's modified Eagle's medium (SigmaAldrich, St. Louis, MO) supplemented with 5\% fetal calf serum (Life Technologies) and 1\% antibiotic-antimycotic solution (Life Technologies).

\section{Scratch-Wound Assay}

Confluent HUVEC and MS-1 monolayers grown in 24-well plates were cultured for 24 hours in starvation medium containing fetal calf serum (Life Technologies; HUVEC, $2 \%$; MS-1, 5\%) and $1 \%$ antibiotic-antimycotic solution (Life Technologies). Assays were performed as previously described $^{11}$ using anti-human ALCAM (R\&D Systems, Abingdon, UK) or goat IgG (all at $10 \mu \mathrm{g} / \mathrm{mL}$ ) in starvation medium. For HUVECs, assays were performed in the presence of human vascular endothelial growth factor A (20 $\mathrm{ng} / \mathrm{mL}$; PeproTech, London, UK) in starvation medium.

\section{Immunohistologic Examination of Murine Tissues}

Immunohistologic examination of murine diaphragms was performed as previously described. ${ }^{11}$ In brief, diaphragm wholemounts were blocked in $1 \%$ bovine serum albumin, $0.05 \%$ sodium azide, $0.01 \%$ Triton X-100, and 5\% normal donkey serum (both from Sigma-Aldrich) in phosphate-buffered saline (PBS) for 1 hour and stained with rat anti-mouse CD31 (BD Bioscience, Franklin Lakes, NJ) in PBS overnight. The next day, diaphragms were washed and incubated for 2 hours with anti-rat Alexa Flour 488-conjugated secondary antibody (InvitroGen). Images were acquired on an LSM 710 confocal microscope (Carl Zeiss Inc., Jena, Germany) using $10 \times$ objective (numerical aperture, 0.3) and analyzed with Fiji software version 1.0 ( $h t t p: / /$ fiji.sc). ${ }^{35}$ To exclusively analyze blood vessels, CD $31^{+}$ lymphatic vessels (identified by their $\mathrm{CD} 31^{\mathrm{dim}}$ staining and large vessel diameter) were removed from the image before analysis.

For immunohistologic analysis of mouse lungs, mice were euthanized and perfused with PBS, followed by a $4 \%$ paraformaldehyde (Sigma-Aldrich) solution for fixation. After 2 days in $4 \%$ paraformaldehyde, lungs were embedded in paraffin. In the case of $\alpha$-smooth muscle actin ( $\alpha$-SMA) staining, lung sections $(6 \mu \mathrm{m})$ were stained on a staining robot (BondMax; Leica Microsystems, Wetzlar, Germany) with anti-mouse $\alpha$-SMA antibody (Sigma-Aldrich), followed by incubation 
with secondary rabbit anti-mouse $\operatorname{IgG}$ (Abcam, Cambridge, UK). Final detection of bound antibody was performed using the Bond Polymer Refine Detection DAB Kit (Leica Microsystems). For the von Willebrand factor (vWF) staining, lung sections were incubated at $60^{\circ} \mathrm{C}$ for 10 minutes, followed by deparaffinization and rehydration. Sections were incubated for 1 hour at room temperature in blocking solution [3\% bovine serum albumin, 0.1\% NP40 (both from Sigma-Aldrich) in PBS]. Subsequently, rabbit anti-mouse vWF (Dako, Glostrup, Denmark) in blocking solution was added overnight at $4^{\circ} \mathrm{C}$. The next day, sections were washed and anti-rabbit Alexa Fluor 594 (InvitroGen) was applied for 1 hour at room temperature in PBS. Sections were mounted using Mowiol (Calbiochem, San Diego, CA). For the quantification of the $\mathrm{vWF}^{+}$or $\alpha-\mathrm{SMA}^{+}$vessel area, five (vWF) or nine ( $\alpha$-SMA) images per lung were acquired. Vessels that were completely visible within the field of view were encircled using Photoshop software version CS5 (Adobe Systems, San Jose, CA), followed by quantification of the vessel area and vessel number.

For the analysis of MC38 tumor vascularization and vessel maturation, OCT-embedded, frozen sections $(6 \mu \mathrm{m})$ were fixed in acetone $\left(2\right.$ minutes at $\left.-20^{\circ} \mathrm{C}\right)$ and methanol $(5$ minutes at $4{ }^{\circ} \mathrm{C}$ ), followed by two washing steps in Tris-buffered saline. Sections were stained with rat anti-mouse CD31 (clone MEC13.3; BD Pharmingen, San Jose, CA) and the chondroitin sulfate proteoglycan neuron-glial 2 (NG2) (polyclonal antibody; Merck) in antibody diluent (Zytomed Systems, Berlin, Germany) overnight at $4^{\circ} \mathrm{C}$. After washing with Tris-buffered saline, Alexa Fluor 488- and 594-coupled secondary antibodies (InvitroGen) were added for detection. Sections were mounted using Mowiol (Calbiochem). For quantification of $\mathrm{CD} 31^{+}$and $\mathrm{CD} 31^{+} \mathrm{NG} 2^{+}$vessels, images of three vascularized areas per tumor nodule were acquired and analyzed using Fiji software. ${ }^{35}$ The area of $\mathrm{CD} 31^{+}$vessels was determined after thresholding. Subsequently, the percentage of vessels that were $\mathrm{NG}_{2}{ }^{+}$among $\mathrm{CD} 31^{+}$vessels was determined.

For the analysis of macrophage infiltration into MC38 tumor nodules, OCT-embedded, frozen sections $(6 \mu \mathrm{m})$ were fixed in acetone $\left(2\right.$ minutes at $-20^{\circ} \mathrm{C}$ ) and methanol (5 minutes at $4^{\circ} \mathrm{C}$ ), followed by two washing steps in PBS. Sections were incubated for 45 minutes at room temperature in blocking solution [ $2 \%$ bovine serum albumin, $5 \%$ normal donkey serum, $0.1 \%$ Triton X-100 (all from Sigma-Aldrich) in PBS]. Subsequently, rat anti-mouse F4/80 (clone BM8; eBioscience, San Diego, CA) and goat anti-mouse CD206 (polyclonal antibody; R\&D Systems) in PBS with 5\% normal donkey serum were added overnight at $4^{\circ} \mathrm{C}$. After washing with PBS, Alexa Fluor 488- and 594-coupled secondary antibodies (InvitroGen) were added for detection. Sections were mounted using Mowiol (Calbiochem). For quantification of $\mathrm{F} 4 / 80^{+}$and $\mathrm{F} 4 / 80^{+} \mathrm{CD} 206^{+}$cells, three images per tumor nodule were acquired and analyzed using Fiji software. ${ }^{35}$

For the quantification of tumor nodule area, frozen MC38 sections were stained with hematoxylin and eosin, and stitched images of the entire tumor nodule were acquired and analyzed using Photoshop (Adobe Systems). Images were acquired with an Axioskop 2 motorized plus microscope (Carl Zeiss Inc.) using the following objectives: $10 \times$ objective, numerical aperture of 0.3 (for lung sections stained for vWF and $\alpha$-SMA); $20 \times$ objective, numerical aperture of 0.5 (for MC38 lung tumor sections stained for CD31/NG2 and F4/80/CD206); and 5x objective; numerical aperture of 0.15 (hematoxylin and eosin staining). The microscope was equipped with an AxioCam MRm monochrome digital camera (Carl Zeiss Inc.) and AxioVision software version 4.4 (Carl Zeiss Inc.).

\section{Immunohistologic Examination of Human Tissues}

Six-micron cryosections of human foreskin and human lungs (Zyagen, San Diego, CA) were analyzed for ALCAM expression. After fixation with acetone $\left(2\right.$ minutes at $\left.-20^{\circ} \mathrm{C}\right)$ and $80 \%$ methanol $\left(5\right.$ minutes at $\left.4{ }^{\circ} \mathrm{C}\right)$, sections were stained with mouse anti-human CD31 (clone JC70A; Dako) or mouse anti-human $\alpha$-SMA-Cy3 (clone 1A4; Sigma-Aldrich) and goat anti-mouse ALCAM (polyclonal antibody; R\&D Systems) or corresponding goat isotype control (InvitroGen) overnight at $4{ }^{\circ} \mathrm{C}$ in a PBS blocking solution containing $2 \%$ bovine serum albumin, 5\% normal donkey serum, and $0.1 \%$ Tween (all from Sigma-Aldrich). After washing, anti-mouse Alexa Fluor 594 and anti-goat Alexa Fluor 647 (InvitroGen) were added for 1 hour at room temperature. Confocal images were acquired using a TCS SP8 microscope (Leica Microsystems) using a $20 \times$ objective (numerical aperture of 0.7 ).

\section{FACS Analysis}

Fluorescence-activated cell sorting (FACS) analysis of in vitro-cultured cells and tissues was performed as previously described. ${ }^{11}$ In brief, in vitro-cultured cells were washed with PBS and detached using Accutase (Sigma-Aldrich). For tissue FACS, tissues were digested in PBS supplemented with $4 \mathrm{mg} /$ $\mathrm{mL}$ collagenase IV (Thermo Fisher Scientific, Waltham, MA) for 1 hour at $37^{\circ} \mathrm{C}$. In the case of lungs, collagenase IV was resuspended in Grey's balanced salt solution (Sigma-Aldrich). Cell suspensions were stained with anti-mouse CD31allophycocyanin, anti-mouse CD45-peridinin chlorophyll protein complex, and anti-mouse podoplanin-phycoerythrin (PE) and corresponding isotype controls (all from BioLegend, San Diego, CA). Dead cells were excluded using Zombie dye (BioLegend). ALCAM expression was detected using staining with goat anti-mouse ALCAM antibody and corresponding Alexa Fluor 488- or PE-labeled secondary antibodies (InvitroGen). Data were acquired on a FACS canto II device (BD Bioscience, Franklin Lakes, NJ) using FACSDiva software version 6.1.3 (BD Bioscience) and analyzed with FlowJo software version 8.7.1 (Tree Star, Ashland, OR).

\section{Homing Studies}

Twelve- to 15-week-old WT or $\mathrm{ALCAM}^{-1-}$ mice were used for homing studies. Before tumor cell injection, tumor 
cells (LLC or B16F10) were stained with $5 \mathrm{mmol} / \mathrm{L}$ carboxyfluorescein succinimidyl ester (CFSE) (InvitroGen) for 15 minutes at $37^{\circ} \mathrm{C}$ in PBS, followed by neutralization of unused dye with equal volumes of media. After cells were washed twice with PBS, mice were injected intravenously with $1 \times 10^{6}$ cells 24 hours later, mice were sacrificed and perfused with PBS, and the lungs were harvested. Lungs were cut into small pieces and digested for 45 minutes at $37^{\circ} \mathrm{C}$ in $4 \mathrm{mg} / \mathrm{mL}$ collagenase IV (Thermo Fisher Scientific) in PBS. Subsequently, the lungs were passed through a 40$\mu \mathrm{m}$ cell strainer and subjected to red blood cell lysis using ammonium-chloride-potassium (ACK) buffer. Lung singlecell suspensions were stained with CD45-allophycocyanin (BioLegend). CD45 ${ }^{-} \mathrm{CFSE}^{+}$tumor cells were quantified by FACS with the help of counting beads (InvitroGen).

\section{Tumor Models}

Twelve- to 15-week-old WT or ALCAM ${ }^{-1-}$ mice were used for tumor studies. For the lung metastasis model, mice were injected intravenously with tumor cells (B16F10-Luc, $1 \times 10^{6}$ cells; LLC, $1.5 \times 10^{5}$ cells; and MC38-Green fluorescent protein, $3 \times 10^{5}$ cells). After 12 to 26 days (B16F10 and LLC, 12 to 14 days; MC38, 26 days) mice were sacrificed and the tumor burden was analyzed. B16F10 tumor growth was monitored in vivo by i.p. injection of luciferin $150 \mathrm{mg} / \mathrm{kg}$ body weight and imaging the luminescent signal in the thorax 20 minutes later with an IVIS Spectrum imaging system (Caliper) under isoflurane anesthesia. At the end of the experiment, mice were sacrificed, and the luciferase signal was measured in excised lungs and in lung single-cell suspensions (see In Vitro Luciferase Activity Assay). For the spontaneous lung metastasis model, mice were injected subcutaneously with LLC, $0.2 \times 10^{6}$ cells. Primary tumors were resected after 21 or 24 days. The metastatic burden was quantified 3 weeks later using an IVIS Spectrum imaging system (Caliper).

\section{In Vitro Luciferase Activity Assay}

Lung tissue was homogenized in lysis buffer containing 25 mmol/L Tris-Cl (pH 7.8; Sigma-Aldrich), 2 mmol/L EDTA (Sigma-Aldrich), $1 \mathrm{mmol} / \mathrm{L}$ dithiothreitol (Promega, Madison, WI), $10 \%$ glycerol (ABCR, Karlsruhe, Germany), $1 \%$ Triton X-100 (Sigma-Aldrich), and one Complete Mini, EDTA-free protease inhibitor tablet (one tablet added to 10 $\mathrm{mL}$ of lysis buffer; Roche, Basel, Switzerland). Samples were homogenized using a TissueLyser (Qiagen, Venlo, the Netherlands; Retsch, Haan, Germany) followed by centrifugation. Luciferase activity was measured with an IVIS Spectrum (Caliper) using $25 \mu \mathrm{L}$ of tissue lysate and $50 \mu \mathrm{L}$ of assay buffer, which consisted of $20 \mathrm{mmol} / \mathrm{L}$ Tris-Cl (Sigma-Aldrich), $1.1 \mathrm{mmol} / \mathrm{L} \mathrm{MgCl}$ (Honeywell Research Chemicals, Mexico City, Mexico), $2.7 \mathrm{mmol} / \mathrm{L} \mathrm{MgSO}_{4} \times$ $7 \mathrm{H}_{2} \mathrm{O}$ (Honeywell Research Chemicals), $0.1 \mathrm{mmol} / \mathrm{L}$ EDTA, $33.3 \mathrm{mmol} / \mathrm{L}$ dithiothreitol (Promega), $530 \mu \mathrm{mol} / \mathrm{L}$ ATP (Sigma-Aldrich), and $400 \mu \mathrm{mol} / \mathrm{L}$ luciferin (Caliper).

\section{Statistical Analysis}

Statistical analysis was performed using Prism software version 6 (GraphPad Software, Inc., La Jolla, CA). Normally distributed data were analyzed using the $t$-test or oneway analysis of variance (more than two groups) and are presented as means \pm SEM. A $\chi^{2}$ test was applied to test for significant differences in the rate of metastases. Significant outliers were identified based on the Grubbs test and excluded. Differences were considered statistically significant when $P<0.05$.

\section{Results}

\section{ALCAM Is Expressed in the Human and Murine Vasculature and Contributes to in Vitro Angiogenesis}

We recently described an in vivo role of ALCAM in the formation of the lymphatic network in mice. ${ }^{11}$ Moreover, several studies have previously reported on the expression of ALCAM in blood vessels ${ }^{7,11,14,15}$ and on its involvement in endothelial cell biology in vitro. ${ }^{11,12}$ In agreement with previous findings, ${ }^{11}$ ALCAM expression was detected in the vasculature of human skin (Figure 1A). Moreover, ALCAMpositive blood vessels were identified in tissue sections of human lung (Figure 1B). High-magnification confocal images of the vasculature in the human lung revealed that ALCAM was primarily expressed in endothelial cells but not in vessel-surrounding mural cells (Supplemental Figure S1, A and B). Interestingly, in the mouse model, FACS analysis performed on tissue single-cell suspensions revealed ALCAM expression in endothelial cells derived from the murine lung (Figure 1C), but not from murine skin (Figure 1D). Moreover, ALCAM was expressed by nonendothelial stromal cells (ie, fractions of $\mathrm{CD} 31^{-} \mathrm{CD}_{4} 5^{-}$podoplanin $^{+}$and $\mathrm{CD} 31^{-} \mathrm{CD} 45^{-}$podoplanin ${ }^{-}$ cells) (Supplemental Figure S1, C and D). In vitro endothelial cell migration assays were performed with ALCAMexpressing HUVECs and with the immortalized murine blood vascular endothelial cell line MS- ${ }^{34}$ (Figure 1, E and F). In both cell types, endothelial cell migration into cell-free areas was significantly reduced in the presence of an ALCAM blocking antibody (Figure 1, G and $\mathrm{H}$ ), supporting the concept that ALCAM supports angiogenic processes in vitro.

\section{ALCAM Contributes to Angiogenesis in Vivo}

To investigate whether ALCAM contributes to angiogenesis in vivo, the blood vasculature in the lung and the diaphragm of $\mathrm{ALCAM}^{-1-}$ mice was analyzed. ${ }^{16}$ Whole-mount analyses in the diaphragm of pups showed that the total area covered by $\mathrm{CD} 31^{+}$blood vessels as well as the mean blood vessel diameter were markedly reduced in $\mathrm{ALCAM}^{-1-}$ compared to WT diaphragms (Figure 2, A-C). Moreover, when staining murine lung sections for the blood vascular marker vWF (Figure 2D), the size of $\mathrm{vWF}^{+}$vessels was profoundly 


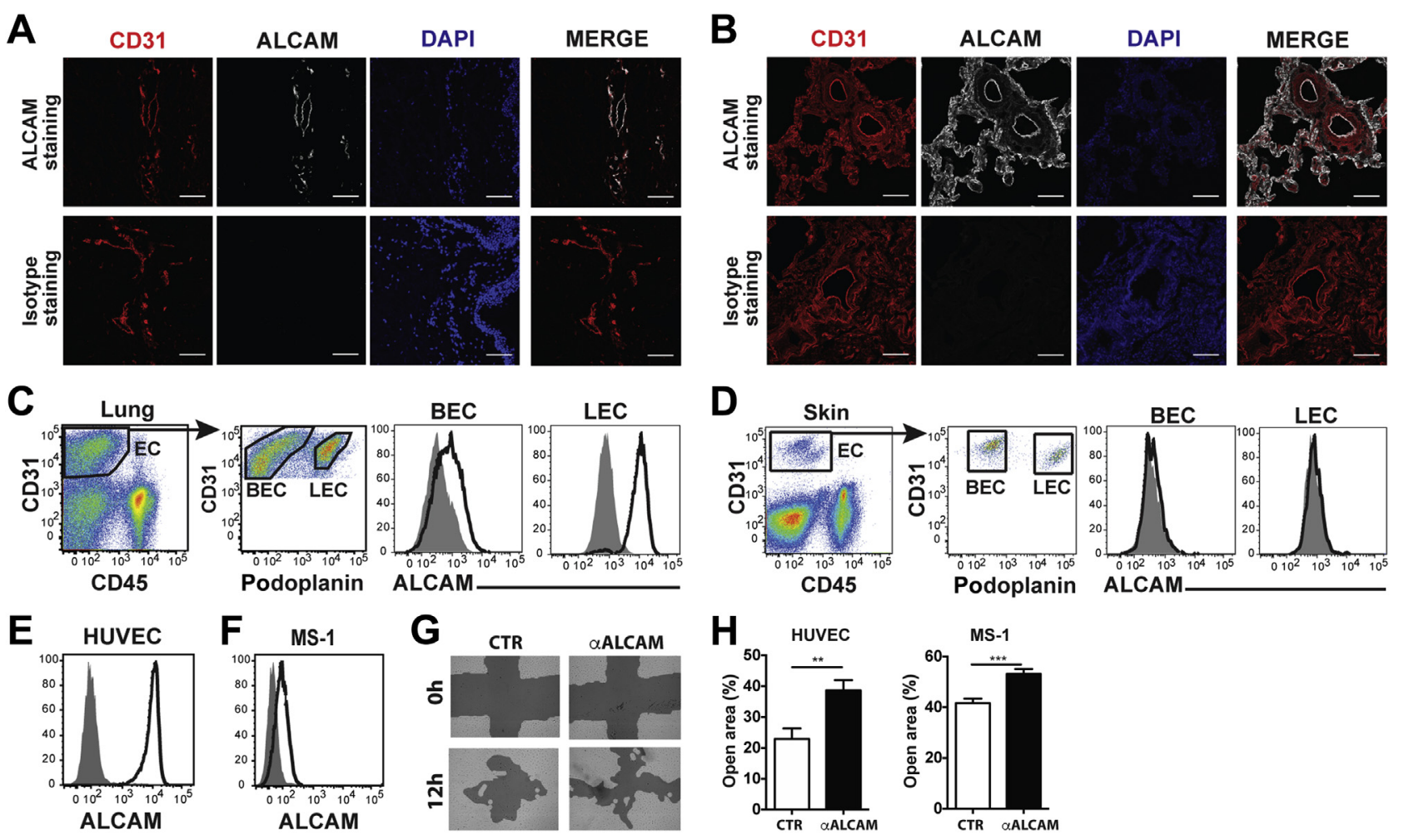

Figure 1 Activated leukocyte cell adhesion molecule (ALCAM) is expressed in the human and murine vasculature and contributes to in vitro angiogenesis. A and B: Immunofluorescence analysis of human skin (A) and lung (B) tissue sections, demonstrating expression of ALCAM in CD31 ${ }^{+}$vessels. ALCAM staining, performed with primary goat anti-ALCAM; isotype staining, performed with primary goat isotype control antibody. Representative images from three skin and two lung biopsy samples are shown. $\mathbf{C}$ and $\mathbf{D}$ : Single-cell suspensions were generated from murine lungs (C) and ear skin (D) and stained for CD31, podoplanin, and CD45. Blood vascular endothelial cells (BECs) and lymphatic endothelial cells (LECs) were identified by gating on CD45 $5^{-}$CD31 $1^{+}$podoplanin ${ }^{-}$cells (BECs) or $\mathrm{CD}^{-} 5^{-} \mathrm{CD} 31^{+}$podoplanin ${ }^{+}$cells (LECs) (outlined). White histogram, $\alpha$ ALCAM staining; gray histogram, isotype control. Representative data from one of three similar experiments are shown. E and F: Fluorescence-activated cell sorting analysis of ALCAM expression in human umbilical vein endothelial cells (HUVECs) (E) and mouse Mile Sven (MS)-1 cells (F). White histogram, ALCAM staining; gray histogram, isotype control. G and H: Scratch-wound assay. A cell-free zone was introduced into confluent HUVEC or MS-1 monolayers, and the effect of ALCAM blockade on scratch closure, which represents migration of bordering LECs into the cell-free zone, was analyzed 12 hours later. G: Representative images taken from an experiment performed with HUVECs. H: Results from HUVEC and MS-1 scratch assays. Data are expressed as means \pm SEM from one of three $\left(\mathbf{H}\right.$, HUVEC) or one of five $(\mathbf{H}$, MS- 1$)$ similar experiments. ${ }^{* *} P<0.01$, $* * * P<0.001$. Scale bars $=100 \mu \mathrm{m}(\mathbf{A}$ and $\mathbf{B})$. CTR, control.

reduced in $\mathrm{ALCAM}^{-1-}$ compared to WT mice (Figure 2E). By contrast, when staining murine lung sections with the pericyte marker $\alpha$-SMA (Figure $2 F$ ), no difference in the size of $\alpha$-SMA ${ }^{+}$vessels, which typically represent the larger vessels, was observed (Figure 2G). However, the total number of $\alpha$-SMA ${ }^{+}$vessels was significantly reduced (Figure $2 \mathrm{H}$ ). Taken together, these results reveal an angiogenetic defect in the lung and diaphragm and suggest general alterations in the blood vasculature of $\mathrm{ALCAM}^{-1-}$ mice.

\section{Growth of B16F10 Lung Metastases Is Reduced in ALCAM $^{-/-}$Mice}

Given the expression of ALCAM on human and murine blood vessels in the lung (Figure 1, B and C) and its impact on in vivo angiogenesis (Figure 2), tumor growth in this organ was investigated next. To this end, mice were injected intravenously with a luciferase-expressing B16F10 melanoma cell line. Subsequent monitoring of luciferase activity over 12 days by IVIS showed that the luciferase signals were consistently lower in $\mathrm{ALCAM}^{-1-}$ compared to WT mice (Figure 3, A and B). The reduced metastatic burden in $\mathrm{ALCAM}^{-1-}$ compared to WT mice was supported at the end of the study by measurements of the luciferase activity in excised lungs (Figure 3C) or in lung homogenates (Figure 3D). No significant differences were found when quantifying visible lung metastases in WT and $\mathrm{ALCAM}^{-/-}$mice (Figure 3E) or in tumor cell-homing studies (Supplemental Figure S2), suggesting that the loss of stromal ALCAM expression did not affect the ability of ALCAM-expressing B16F10 cells (Figure $3 \mathrm{~F}$ ) to home and seed to the lung. By contrast, the overall area covered by visible metastases was profoundly reduced in $\mathrm{ALCAM}^{-/-}$mice (Figure 3G). Moreover, when analyzing the size distribution of metastases in both genotypes, it was observed that $\mathrm{ALCAM}^{-/-}$mice had almost no large metastases (defined as metastases with a diameter of $>350$ $\mu \mathrm{m})$, but an increased number of small metastases (diameter $<200 \mu \mathrm{m}$ ) (Figure $3 \mathrm{H}$ ). Taken together, these findings suggest a growth disadvantage of $\mathrm{B} 16 \mathrm{~F} 10$ metastases in the lungs of $\mathrm{ALCAM}^{-1-}$ mice. 
A

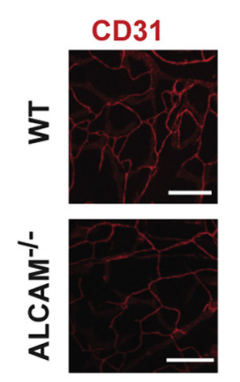

E

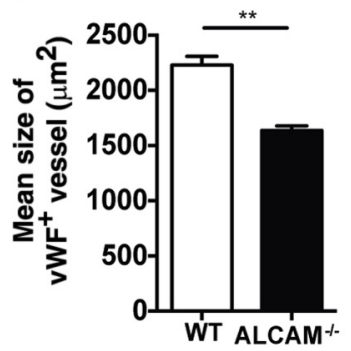

B

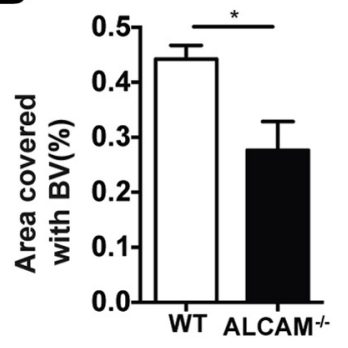

$\mathbf{F}$

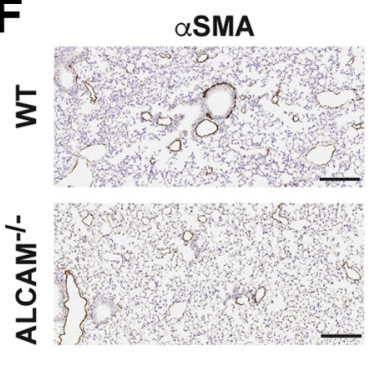

C
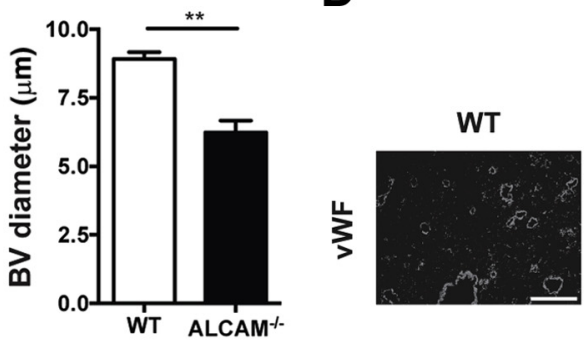

ALCAM $^{-1-}$

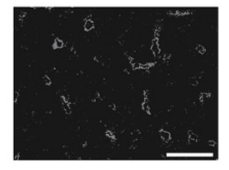

Figure 2 Activated leukocyte cell adhesion molecule (ALCAM) ${ }^{-/-}$mice display an abnormal vascular phenotype in the diaphragm and the lung in vivo. A-C Paraformaldehyde-fixed diaphragms of 6-day-old wild-type (WT) or $\mathrm{ALCAM}^{-1-}$ pups were immunofluorescently stained for the panendothelial marker CD31. For analysis of blood vessels (BV) only, CD31 ${ }^{+}$lymphatic vessels (identified by their CD31 ${ }^{\text {dim }}$ staining and large vessel diameter) were removed from the image using Fiji software version 1.0. A: Representative images taken from WT and ALCAM ${ }^{-/}$diaphragms. B and C: Quantification of the total area covered by CD31 ${ }^{+}$ blood vessels (B) and the diameter of CD31+ blood vessels (C). D-H: Image-based morphometric analysis to quantify von Willebrand factor (vWF) staining (D) and $\alpha$-smooth muscle actin ( $\alpha$-SMA) staining (F) in paraformaldehyde (PFA)-fixed lung sections of WT or ALCAM ${ }^{-/-}$mice. E: Analysis of the size of $v W F^{+}$ vessels. $\mathbf{G}$ and $\mathbf{H}$ : Analyses of the size $(\mathbf{G})$ and number $(\mathbf{H})$ of $\alpha-\mathrm{SMA}^{+}$vessels in WT and ALCAM ${ }^{-1-}$ mice. Data are expressed as means \pm SEM. $n=7$ to 9 mice per group (B and $\mathbf{C}) ; n=3$ mice per group $(\mathbf{E}, \mathrm{vWF}) ; n=4$ to 5 mice per group $(\mathbf{G}$ and $\mathbf{H}, \alpha-\mathrm{SMA})$. ${ }^{*} P<0.05,{ }^{*} P<0.01$. Scale bars $=200 \mu \mathrm{m}(\mathbf{A}, \mathbf{D}$, and $\mathbf{F})$.

\section{Stromal ALCAM Deficiency Reduces MC38 Tumor Growth and Angiogenesis}

To confirm the observed tumor growth defect in a further model, similar experiments were performed with MC38 adenocarcinoma cells (Figure 4A), which form fewer but larger metastases in the lungs on i.v. injection (Figure 4B). When dissecting the lungs 24 to 28 days after tumor cell injection, no difference in metastasis numbers was observed between the genotypes (Figure 4C). However, the mean lung tumor nodule weight was profoundly reduced in $\mathrm{ALCAM}^{-/-}$ mice (Figure 4D), supporting the concept of a metastatic growth defect previously observed in the B16F10 model. In line with the reduced tumor weight, hematoxylin and eosin staining revealed that the mean tumor area (Figure 4E) and the overall percentage of large tumors (Figure 4, F and G) were reduced in $\mathrm{ALCAM}^{-/-}$compared to WT mice. To investigate whether the reduction in tumor size was caused by a defect in angiogenesis, tumor vascularization was analyzed by immunofluorescence. No lymphatic vessel endothelial hyaluronic acid 1-positive $\left(\right.$ LYVE- $1^{+}$) lymphatic vessels were detected within the tumor nodules (data not shown). Therefore, all vessels stained by the pan-endothelial marker CD31 were assumed to be blood vessels. In support of our hypothesis, the tumor area covered by $\mathrm{CD} 31^{+}$vessels was significantly reduced in $\mathrm{ALCAM}^{-/-}$mice, indicating a defect in tumor angiogenesis (Figure $4 \mathrm{H}$ ). Tumor blood vessels are known to grow in an uncontrolled manner and typically display an immature phenotype, as manifested by reduced pericyte coverage. ${ }^{36}$ When co-staining tumor nodule sections for the pericyte marker melanoma-associated antigen $\mathrm{NG}^{36,37}$ and $\mathrm{CD} 31$, it was observed that the vasculature of $\mathrm{ALCAM}^{-1-}$ mice displayed an increased number of mature, that is, $\mathrm{NG}^{+}$ vessels (Figure 4I). Overall, these findings suggest that, in comparison to the tumor vasculature of WT mice, $\mathrm{ALCAM}^{-1-}$ mice displayed less aberrant tumor neoangiogenesis. Notably, the numbers of tumor-infiltrating $\mathrm{F} 4 / 80^{+}$and of $\mathrm{F} 4 /$ $80^{+} \mathrm{CD}^{206^{+}}$M2-like macrophages, ${ }^{38}$ which are considered proangiogenic, ${ }^{39}$ were similar in both genotypes (Supplemental Figure S3), suggesting that these cells did not contribute to the differences in tumor neovascularization observed between WT and $\mathrm{ALCAM}^{-/-}$mice.

\section{Stromal ALCAM Deficiency Reduces LLC Homing and Tumor Growth in the Lungs}

To confirm the observed tumor growth defect in a further model, similar i.v. metastasis studies were performed using LLC cells, which express high levels of ALCAM (Figure 5A). Also on LLC injection, a growth defect at the level of single metastases was observed in the lungs of ALCAM $^{-1-}$ compared to WT mice (Figure 5, B and C). Moreover, in comparison to WT mice, total numbers of LLC metastases were significantly reduced in the lungs of 

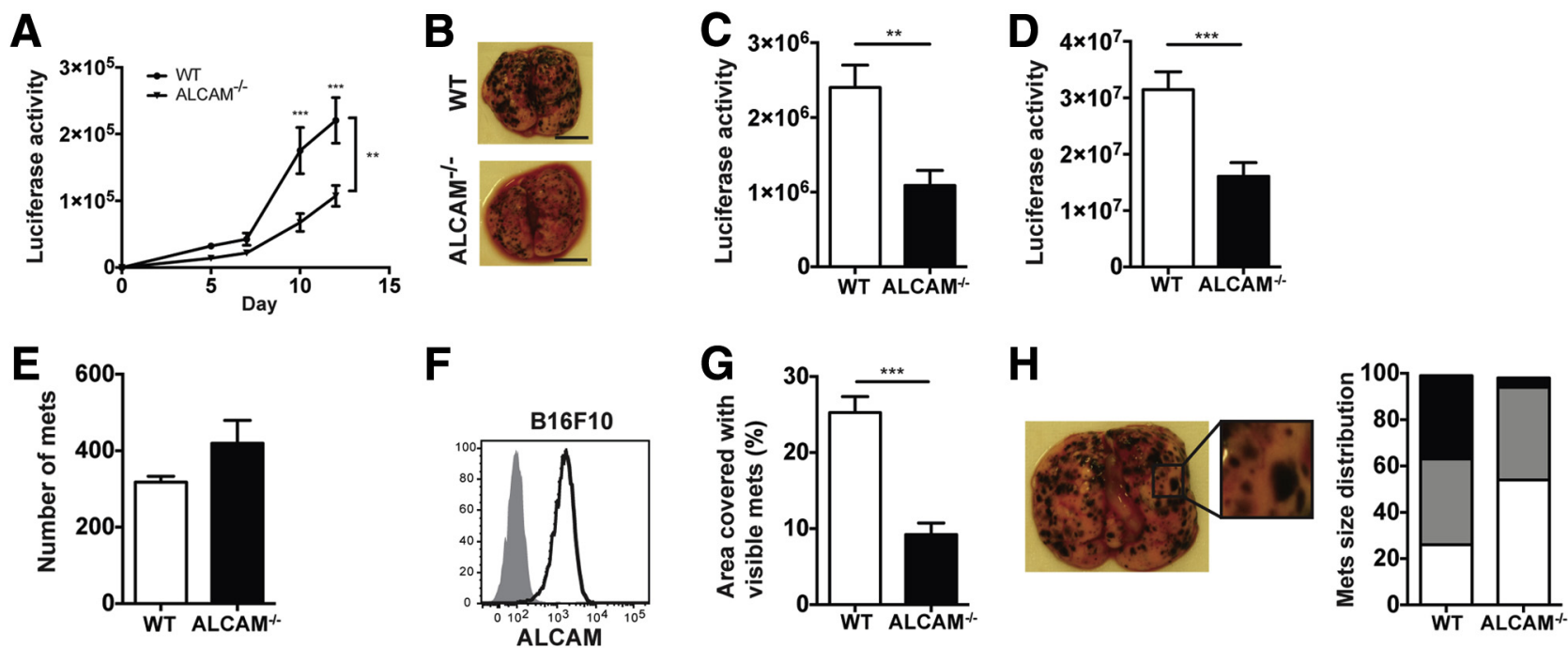

Figure 3 Stromal activated leukocyte cell adhesion molecule (ALCAM) deficiency reduces lung metastasis growth in a B16F10 model. A: Mice were injected intravenously with luciferase-expressing B16F10 tumor, $1 \times 10^{6}$ cells, and tumor growth was monitored over time by IVIS (Caliper, Hopkinton, MA)-based analysis of in vivo luciferase activity. B: Representative images of lungs from wild-type (WT) and ALCAM ${ }^{-/-}$mice at the end of the study, revealing the coverage with melanin-producing B16F10 tumor cells. C and D: IVIS-based analysis of ex vivo luciferase activity in excised lungs (C) and lung homogenates (D). E: Manual counting of visible lung metastases. F: Fluorescence-activated cell sorting analysis of ALCAM expression of in vitro-cultured B16F10. White histogram, anti-ALCAM staining; gray histogram, isotype control. G: Assessment of the area covered by visible metastases (mets). H: Distribution of small (diameter $<200 \mu \mathrm{m}$ ), medium (diameter $<350 \mu \mathrm{m}$ ), and large (diameter $>350 \mu \mathrm{m}$ ) metastases in lungs of WT or ALCAM ${ }^{-1-}$ mice. An exemplary lung image is shown on the left (additional magnification of the boxed area is also shown); quantification is provided on the right (white, gray, or black coding for small, medium, or large metastases, respectively). Data are expressed as means \pm SEM from one of three similar experiments. $n=9$ to 10 mice per group. ${ }^{* * P}<0.01,{ }^{* * *} P<0.001$. Scale bars $=5 \mathrm{~mm}(\mathbf{B})$.

$\mathrm{ALCAM}^{-/-}$mice (Figure 5D). For investigation of potential differences in tumor cell seeding to the lung, fluorescently labeled LLC cells were injected intravenously and tumor cell numbers were quantified in the lungs after 24 hours by FACS. This analysis revealed that LLC homing into the lungs was significantly reduced in $\mathrm{ALCAM}^{-1-}$ compared to WT mice (Figure 5, E and F).

\section{Stromal ALCAM Deficiency Leads to Reduced Spontaneous Metastases to the Lung and to Tumor- Draining LNS}

In a next step we set out to investigate the metastatic process in a more physiological context. To this end, luciferaseexpressing LLC cells were implanted subcutaneously in the flank of WT and $\mathrm{ALCAM}^{-1-}$ mice, and tumors were allowed to grow for 21 to 24 days. Subsequently, tumors were resected, and spontaneous metastasis to different organs was analyzed 3 weeks later. Surprisingly, primary LLC tumors implanted subcutaneously displayed a moderate growth advantage in $\mathrm{ALCAM}^{-1-}$ compared to WT control mice (Figure 6, A and B). No difference in blood vessel density in primary tumors was observed between ALCAM $^{-1-}$ and WT mice (Figure 6C). In fact, ALCAM was not detected in the LLC tumor vasculature (Figure 6D), in line with our previous observation that ALCAM is not expressed in the murine dermal vasculature under physiological conditions (Figure 1D). To allow for a better comparison of the spontaneous metastasis process, groups of mice with similarly sized tumors were generated.
Specifically, only WT and $\mathrm{ALCAM}^{-1-}$ mice with primary tumors ranging from 200 to $1000 \mathrm{mg}$ at the time point of resection were selected and kept in the study (Figure 6E). Three weeks after primary tumor resection, all animals were sacrificed, and luciferase activity in the lung, liver, and inguinal lymph nodes (LNs) was measured. This analysis revealed a significant reduction in the overall metastatic burden in $\mathrm{ALCAM}^{-1-}$ mice compared to WT controls (Figure 6, F-J, and Supplemental Figure S4). In agreement with the reduced number of tumor nodules and tumor cell homing observed on injection of LLC intravenously (Figure 5, $\mathrm{D}-\mathrm{F}$ ), a dramatic reduction in tumor metastasis to the lungs was observed in $\mathrm{ALCAM}^{-/-}$mice (Figure 6H). Interestingly, metastasis to tumor-draining LNs was also significantly reduced (Figure 6I), whereas no difference in the rate of metastasis to the liver was observed (Figure 6J). Taken together, our work reveals a novel contribution of stromally expressed ALCAM in supporting metastatic spread and tumor outgrowth in the lungs and tumor-draining LNs.

\section{Discussion}

In this study we investigated whether and how the expression of ALCAM by cells that form the stromal tumor microenvironment contributes to tumor growth and metastatic spread. Various studies have documented the relevance of tumor cell-expressed ALCAM to tumor cell migration and invasion, ${ }^{25,40-42}$ and metastasis. ${ }^{3,23,25}$ On the other hand, 

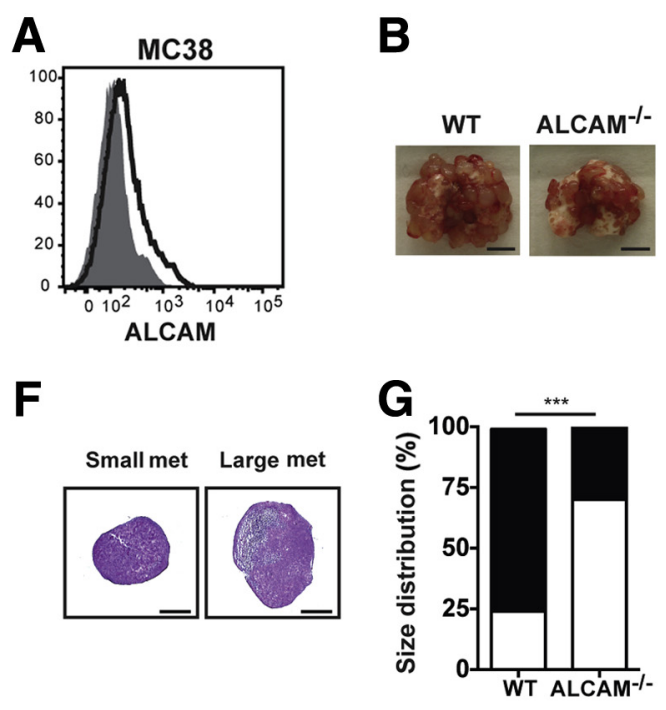
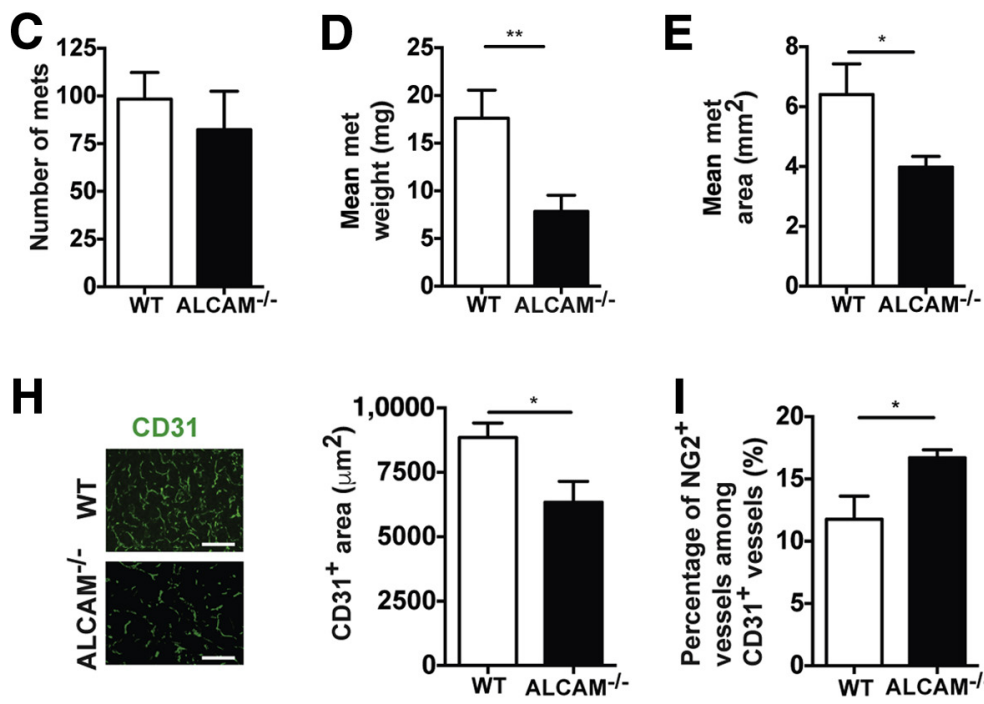

Figure 4 Stromal activated leukocyte cell adhesion molecule (ALCAM) deficiency reduces MC38 tumor growth and angiogenesis. Mice were injected intravenously with MC38 tumor, $3 \times 10^{5}$ cells, and the tumor burden was quantified after 24 to 26 days. A: Fluorescence-activated cell sorting analysis of ALCAM expression by in vitro-cultured MC38 cells. White histogram, anti-ALCAM staining; gray histogram, isotype control. B: Representative images of tumorbearing lungs of wild-type (WT) and ALCAM ${ }^{-/-}$mice. C: Quantification of the number of metastases (mets). D: Mean weight of the 12 largest excised metastases per mouse. Pooled data from three similar experiments are shown. E-G: Sections of the 12 biggest metastases were stained with hematoxylin and eosin, and mean metastasis size was measured (E). F and G: Metastases were grouped into the category small (white; diameter $<2.5 \mathrm{~mm})$ or large (black; diameter $>2.5 \mathrm{~mm}$ ). F: Representative images of a small and a large metastasis. G: Percentage-based distribution of metastasis sizes according to genotype. H: Metastasis sections were stained for CD31, and the CD31 $1^{+}$area was quantified. I: Metastasis sections were stained for CD31 and melanoma-associated

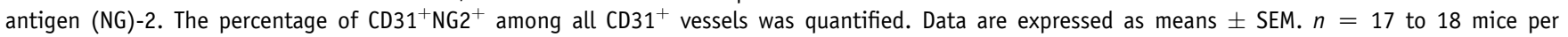
group (D); $n=4$ to 5 mice per group (E-I). ${ }^{*} P<0.05$, ${ }^{*} P<<0.01$, and ${ }^{* *} P<0.001$. Scale bars: $5 \mathrm{~mm}(\mathbf{B}) ; 1 \mathrm{~mm}(\mathbf{F}) ; 200 \mu \mathrm{m}(\mathbf{H})$.

several studies have reported on the expression and function of ALCAM in leukocytes ${ }^{6-8,10}$ and in endothelial cells. ${ }^{8,11,12,26}$ Given that these cells are important constituents of the tumor stroma, the latter findings indirectly suggest a more complex role of ALCAM in tumor growth and progression. Using ALCAM-deficient mice we now show for the first time that not only tumor cell-expressed but also stromally expressed ALCAM may alter tumor growth and metastatic spread by affecting tumor angiogenesis and tumor cell homing.

Experiments in three different i.v. pulmonary metastasis models (ie, B16F10, LLC, and MC38) showed that tumor growth in the lung was consistently reduced in $\mathrm{ALCAM}^{-1-}$ compared to WT mice. Expansion of tumors is highly dependent on the formation of blood vessels. ${ }^{43}$ Analysis of the blood vasculature in the lungs and diaphragm of $\mathrm{ALCAM}^{-1-}$ mice showed that the loss of ALCAM indeed compromised the formation of the blood vascular network in vivo. This finding was further substantiated by our immunohistologic analysis of lung tumor nodules in the MC38 metastasis model, which supported the concept that the reduced tumor growth observed in $\mathrm{ALCAM}^{-1-}$ mice was associated with a defect in tumor angiogenesis: The absence of ALCAM expression on stromal cells led to a reduction in tumor blood vessel density and increased the proportion of mature and likely quiescent vessels. Whether this angiogenetic defect is entirely dependent on the lack of ALCAM expression in the blood vasculature or is potentially also supported by the lack of ALCAM on other stromal cells needs to be explored further.
Our study revealed that the blood vasculature was compromised in the lungs of $\mathrm{ALCAM}^{-/-}$mice. This finding might suggest that the reduced metastatic burden observed in our i.v. metastasis models may simply be explained by anatomic differences in the lungs of $\mathrm{ALCAM}^{-/-}$compared to WT mice. However, tumor nodule numbers did not consistently decrease in $\mathrm{ALCAM}^{-1-}$ mice in the three different i.v. metastasis models investigated. In fact, significant reductions in tumor nodule numbers and in tumor cell homing were observed only with LLC, both on i.v. injection of tumor cells (Figure 5, E and F) as well as in the more physiological model of spontaneous metastasis from s.c. grafted primary tumors (Figure $6 \mathrm{H}$ ). This finding could be used to argue against a mere anatomic explanation for the reduced metastatic burden observed in the lungs of $\mathrm{ALCAM}^{-1-}$ mice. The exact molecular interaction partners that may account for the homing defect observed in the case of LLC are not clear at this point. ALCAM is known to engage in homophilic as well as heterophilic interactions. ${ }^{4-6}$ Given that LLC and B16F10 cells expressed similar levels of ALCAM (Figures 5A and 3F), but that a homing defect was observed only in the LLC model (Figure 5, E and F and Supplemental Figure S2), it is likely that tumor cell homing to the lungs does not depend on homophilic ALCAM-ALCAM interactions. Therefore, differential expression of other ALCAM binding partners $^{4-6}$ might explain the differences in the ALCAM dependence of tumor-cell homing to the lung that was observed in the B16F10 and LLC models. Of interest in this 
A

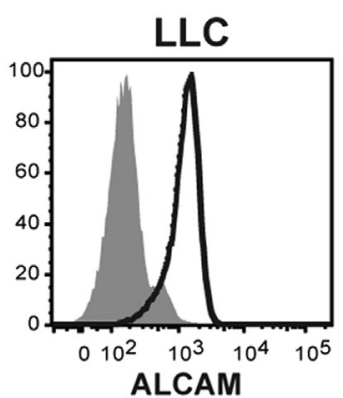

E

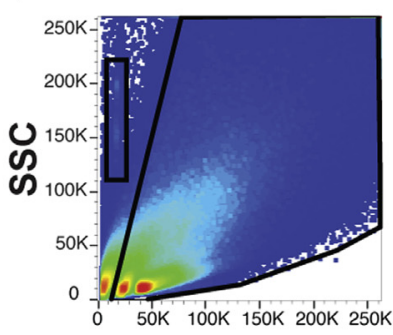

FSC
B
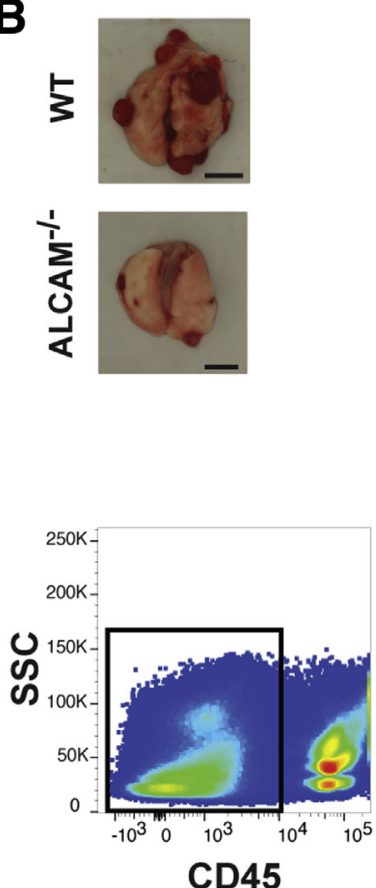

C
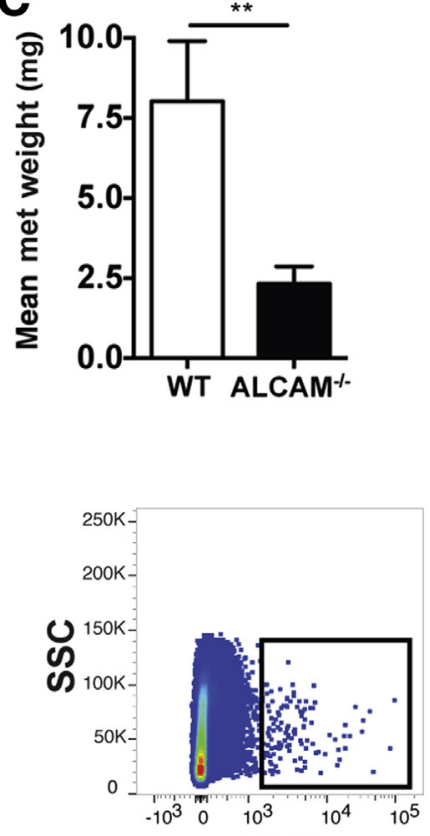

FITC
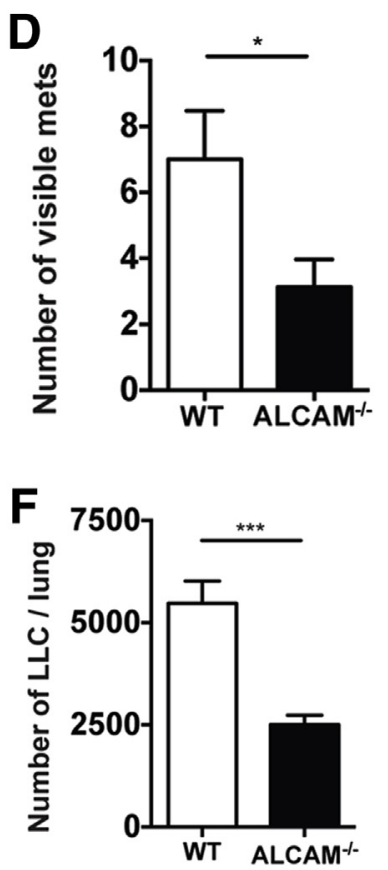

Figure 5 Stromal activated leukocyte cell adhesion molecule (ALCAM) deficiency reduces Lewis lung carcinoma (LLC) homing and tumor growth in the lungs. A: Fluorescence-activated cell sorting (FACS) analysis of ALCAM expression of in vitro-cultured LLC. White histogram $\alpha A L C A M$ staining; gray histogram, isotype control. B-D: Wild-type (WT) and ALCAM ${ }^{-/-}$mice were injected with i.v. LLC, $1.5 \times 10^{5}$ cells, and the metastatic burden in the lung was analyzed on days 12 to 14. B: Images of tumor-bearing lungs at the end of the study. C: Mean weight of all excised metastases (met). D: Total number of metastases in WT compared to $\mathrm{ALCAM}^{-/-}$mice. Pooled data from two independent experiments are shown. E and F: Mice were injected with i.v. carboxyfluorescein succinimidyl ester (CFSE)-labeled LLC, $1 \times 10^{6}$ cells, followed by FACS analysis of lung single-cell suspensions after 24 hours. E: Gating scheme: tumor cells were identified

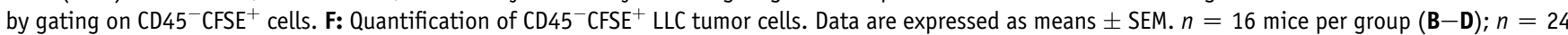
to 25 mice per group (E and $\mathbf{F}$ ). ${ }^{*} P<0.05,{ }^{*} P<0.01$, and ${ }^{* *} P<0.001$. Scale bars $=5$ mm (B). FITC, fluorescein isothiocyanate; FSC, forward scatter; SSC, side scatter.

regard is a separate study that recently identified a role of the ALCAM binding partner L1CAM in the adhesion of breast cancer cells to ALCAM-expressing blood vascular endothelium in vitro. ${ }^{44}$ However, we presently do not know whether differences in L1CAM expression might explain the homing phenotypes observed in our models. Moreover, besides L1CAM and other ALCAM-binding partners, potentially also other adhesion molecules expressed on the tumor cells may compensate for the loss of endothelial ALCAM expression during tumor cell homing. Finally, it is also possible that alterations in tumor cell homing might be caused indirectly by leukocytes that contribute to the tumor cell extravasation process. ${ }^{33,45-49}$

Surprisingly, the growth of s.c. grafted primary tumors was slightly increased in $\mathrm{ALCAM}^{-1-}$ compared to WT mice. In contrast to the angiogenetic defect observed in the lungs, which likely resulted in reduced growth of pulmonary tumor nodules, angiogenesis was not compromised in s.c. grafted tumors (Figure 6C). This finding is in line with our observation that in mice ALCAM is not expressed in the vasculature of the dermis or of s.c. grafted tumors. The fact that loss of ALCAM had an overall growth-promoting effect on s.c. grafted tumors suggests that ALCAM expression in the tumor stroma not only supports angiogenesis (if expressed in the vasculature) but also exerts tumorsuppressive functions. Although not further investigated in this study, it is likely that a loss of ALCAM might compromise the antitumor immune response. For example, ALCAM has been shown to support T-cell activation by stabilizing the immunologic synapse. 9,10,50 Moreover, ALCAM has been implicated in leukocyte extravasation across blood vascular endothelium. ${ }^{7,8}$ Interestingly, in addition to reducing spontaneous metastasis from primary LLC tumors to the lungs (Figure 6H), loss of ALCAM also appeared to reduce the rate of LLC metastasis to draining LNs (Figure 6I) but not to the liver (Figure 6J). ALCAM expression has been detected in the vasculature of the skindraining $\mathrm{LNs}^{11}$ and in the liver (data not shown). ${ }^{15}$ The reason why ALCAM deficiency did not affect LLC metastasis to the liver is unclear but may be linked to the expression of other adhesion molecules in the hepatic vasculature, which might compensate for the loss of ALCAM, or, alternatively, linked to the particular blood flow conditions in the liver. In the case of LN metastasis, it remains unclear at this point whether metastasis occurred via the blood vasculature, or rather via tumor-draining lymphatic vessels. Given that the murine dermal vasculature does not express ALCAM, a defect in the lymphatic 


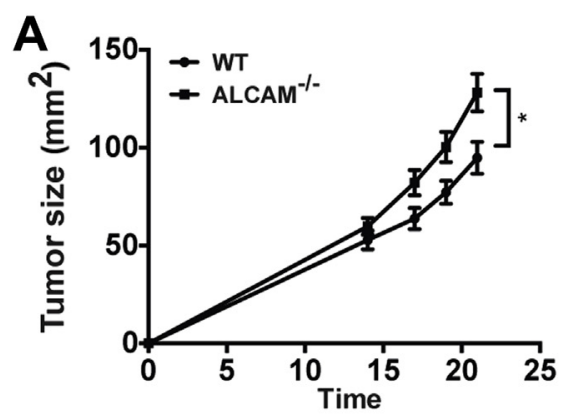

D
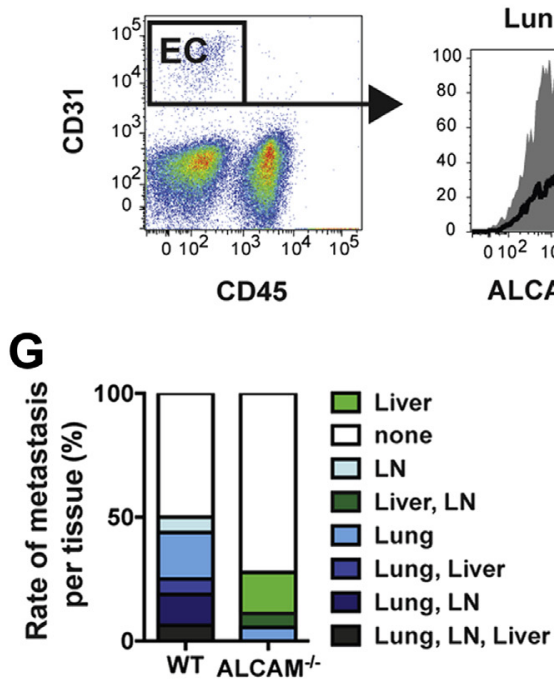
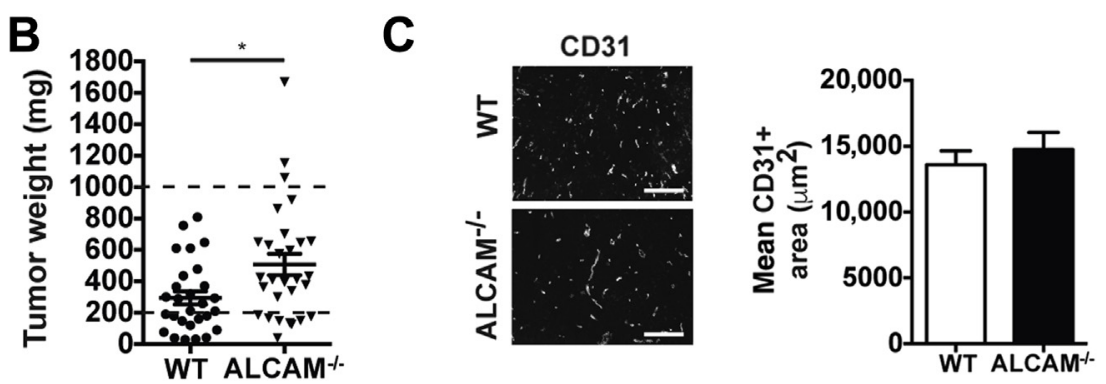

$\mathbf{F}$
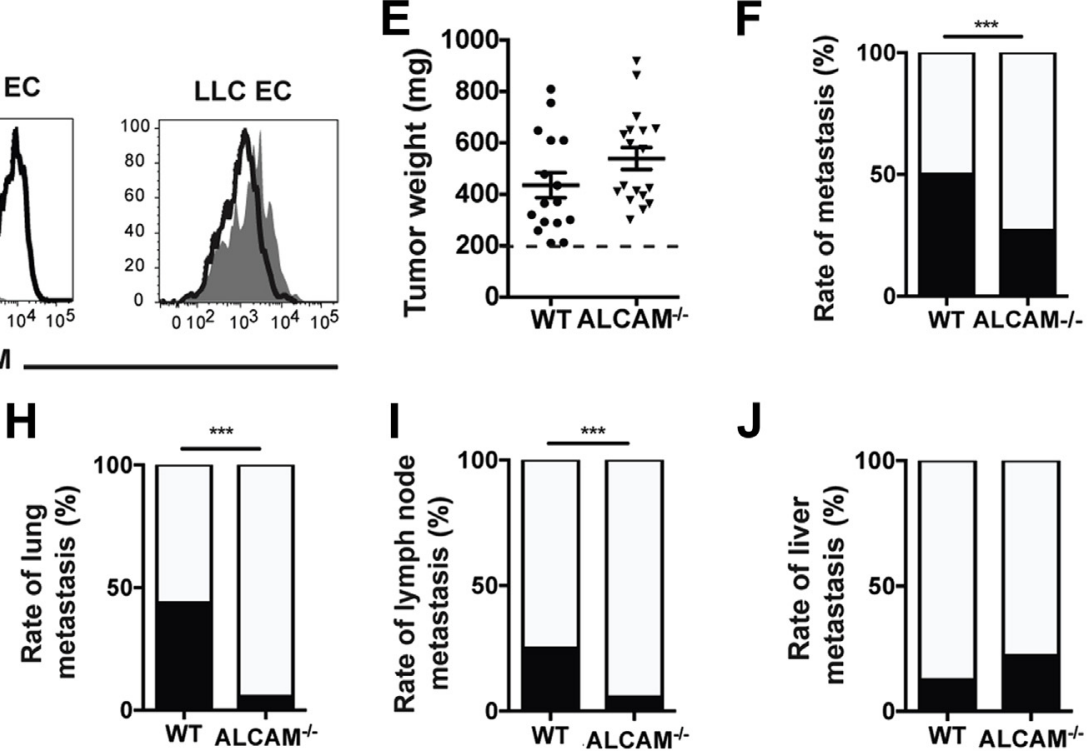

Figure 6 Stromal activated leukocyte cell adhesion molecule (ALCAM) deficiency leads to reduced spontaneous metastases to the lung. A-D: Mice were injected subcutaneously with luciferase-expressing Lewis lung carcinoma (LLC), $2 \times 10^{5}$ cells, and primary tumors were resected after 21 to 24 days. A: Primary tumor growth in wild-type (WT) and ALCAM ${ }^{-1-}$ mice. B: Quantification of the excised primary tumor weight. Each dot represents one mouse. Pooled data from two independent experiments are shown (A and B). C: Tumor vascularization was assessed by quantifying the area of CD31 $1^{+}$vessels. D: Fluorescence-activated cell sorting analysis of ALCAM expression on single-cell suspensions of endothelial cells (ECs) (CD45 ${ }^{-}$CD31 $1^{+}$) derived from lungs or from s.c. growing primary LLC tumors. White histogram, anti-ALCAM staining; gray histogram, isotype control. Data are from 3 mice. E-J: Mice with tumors ranging between 200 and $1000 \mathrm{mg}$ (between dashed lines in B) on the day of resection were included in the subsequent monitoring of spontaneous metastasis. Mice were sacrificed 3 weeks after primary tumor resection, and the metastatic burden was analyzed by IVIS (Caliper, Hopkinton, MA)-based measurement of luciferase activity in the lung, liver, and inguinal lymph node (LN). E: Mice with tumors ranging between 200 and $1000 \mathrm{mg}$ (between dashed lines in B) on the day of resection were included in the subsequent study to monitor spontaneous metastasis. Each dot represents one mouse. F: Quantification of the overall rate of metastasis in ALCAM $^{-1-}$ and WT mice. Black, mice with metastases detected in at least one organ; white, mice with no detectable metastases. G: Same as in $\mathbf{F}$, but revealing the distribution of metastases in specific organs. H-J: Rates of lung $(\mathbf{H}), \mathrm{LN}(\mathbf{I})$, and liver $(\mathbf{J})$ metastases in WT and ALCAM ${ }^{-1-}$ mice. Pooled data from two independent experiments are shown. Data are expressed as means \pm SEM. $n=28$ to 29 mice per group (A and $\mathbf{B}) ; n=16$ to 19 mice per group (C); $n=3$ mice (D); $n=16$ to 18 mice per group (E-J); $n=16$ to 19 mice per group $(\mathbf{C}) ; n=28$ to 29 mice per group (A and $\mathbf{B})$. ${ }^{*} P<0.05,{ }^{* *} P<0.001$. Scale bars $=200 \mu \mathrm{m}$.

migration of tumor cells may only have occurred at the level of the $\mathrm{ALCAM}^{+}$lymphatics in the LN. It is worth noting that in the lung and also in the diaphragm ALCAM was found to be expressed at higher levels in lymphatic vessels compared to blood vessels (Figure 1C and data not shown). Thus, it is perceivable that in other murine tissues, or in human skin in which ALCAM is expressed in the lymphatic vasculature (Figure 1A), ${ }^{11}$ ALCAM expression by (peri) tumoral lymphatics might directly affect tumor cell metastasis to draining LNs.

Overall, our data reveal a novel contribution of stromal ALCAM expression to tumor growth and metastatic spread and suggest an important role of ALCAM expressed in blood vessels in supporting tumor angiogenesis. Moreover, our findings reveal that ALCAM expression in the lung may additionally support tumor cell homing and seeding to this organ. These findings suggest that ALCAM blockade may be beneficial for inhibiting tumor cell metastasis and tumor (lymph)angiogenesis. The fact that ALCAM expression was detected in the vasculature of human lung and skin (Figure 1, A and B) strengthens the potential translational relevance of our findings.

\section{Acknowledgments}

We thank Simone Haener (ETH Zurich) for excellent technical assistance and the staff of the ETH Zurich Rodent 
Center HCI and University of Zurich Laboratory Animal Service Center for animal husbandry. The B16F10-luc2 cell line was kindly provided by Dr. Michael Detmar, ETH Zurich.

\section{Supplemental Data}

Supplemental material for this article can be found at http://dx.doi.org/10.1016/j.ajpath.2017.07.008.

\section{References}

1. Cavallaro U, Christofori G: Cell adhesion and signalling by cadherins and Ig-CAMs in cancer. Nat Rev Cancer 2004, 4:118-132

2. Reymond N, d'Agua BB, Ridley AJ: Crossing the endothelial barrier during metastasis. Nat Rev Cancer 2013, 13:858-870

3. Wai Wong C, Dye DE, Coombe DR: The role of immunoglobulin superfamily cell adhesion molecules in cancer metastasis. Int J Cell Biol 2012, 2012:340296

4. Buhusi M, Demyanenko GP, Jannie KM, Dalal J, Darnell EP, Weiner JA, Maness PF: ALCAM regulates mediolateral retinotopic mapping in the superior colliculus. J Neurosci 2009, 29: 15630-15641

5. Delgado VM, Nugnes LG, Colombo LL, Troncoso MF, Fernandez MM, Malchiodi EL, Frahm I, Croci DO, Compagno D, Rabinovich GA, Wolfenstein-Todel C, Elola MT: Modulation of endothelial cell migration and angiogenesis: a novel function for the "tandem-repeat" lectin galectin-8. FASEB J 2011, 25:242-254

6. Aruffo A, Bowen MA, Patel DD, Haynes BF, Starling GC, Gebe JA, Bajorath J: CD6-ligand interactions: a paradigm for SRCR domain function? Immunol Today 1997, 18:498-504

7. Cayrol R, Wosik K, Berard JL, Dodelet-Devillers A, Ifergan I, Kebir H, Haqqani AS, Kreymborg K, Krug S, Moumdjian R, Bouthillier A, Becher B, Arbour N, David S, Stanimirovic D, Prat A: Activated leukocyte cell adhesion molecule promotes leukocyte trafficking into the central nervous system. Nat Immunol 2008, 9: 137-145

8. Masedunskas A, King JA, Tan F, Cochran R, Stevens T, Sviridov D, Ofori-Acquah SF: Activated leukocyte cell adhesion molecule is a component of the endothelial junction involved in transendothelial monocyte migration. FEBS Lett 2006, 580:2637-2645

9. Hassan NJ, Barclay AN, Brown MH: Frontline: optimal T cell activation requires the engagement of CD6 and CD166. Eur J Immunol 2004, 34:930-940

10. Zimmerman AW, Joosten B, Torensma R, Parnes JR, van Leeuwen FN, Figdor CG: Long-term engagement of CD6 and ALCAM is essential for T-cell proliferation induced by dendritic cells. Blood 2006, 107:3212-3220

11. Iolyeva M, Karaman S, Willrodt AH, Weingartner S, Vigl B, Halin C: Novel role for ALCAM in lymphatic network formation and function. FASEB J 2013, 27:978-990

12. Ikeda K, Quertermous T: Molecular isolation and characterization of a soluble isoform of activated leukocyte cell adhesion molecule that modulates endothelial cell function. J Biol Chem 2004, 279: 55315-55323

13. Lecuyer MA, Saint-Laurent O, Bourbonniere L, Larouche S, Larochelle C, Michel L, Charabati M, Abadier M, Zandee S, Haghayegh Jahromi N, Gowing E, Pittet C, Lyck R, Engelhardt B, Prat A: Dual role of ALCAM in neuroinflammation and blood-brain barrier homeostasis. Proc Natl Acad Sci U S A 2017, 114: E524-E533

14. Ofori-Acquah SF, King J, Voelkel N, Schaphorst KL, Stevens T: Heterogeneity of barrier function in the lung reflects diversity in endothelial cell junctions. Microvasc Res 2008, 75:391-402
15. Schliemann C, Roesli C, Kamada H, Borgia B, Fugmann T, Klapper W, Neri D: In vivo biotinylation of the vasculature in B-cell lymphoma identifies BST-2 as a target for antibody-based therapy. Blood 2010, 115:736-744

16. Weiner JA, Koo SJ, Nicolas S, Fraboulet S, Pfaff SL, Pourquie O, Sanes JR: Axon fasciculation defects and retinal dysplasias in mice lacking the immunoglobulin superfamily adhesion molecule BEN/ALCAM/SC1. Mol Cell Neurosci 2004, 27:59-69

17. Patel DD, Wee SF, Whichard LP, Bowen MA, Pesando JM, Aruffo A, Haynes BF: Identification and characterization of a 100-kD ligand for CD6 on human thymic epithelial cells. J Exp Med 1995, $181: 1563-1568$

18. Singer NG, Mitra R, Lialios F, Richardson BC, Marks RM, Pesando JM, Fox DA, Nickoloff BJ: CD6 dependent interactions of T cells and keratinocytes: functional evidence for a second CD6 ligand on gamma-interferon activated keratinocytes. Immunol Lett 1997, 58 : $9-14$

19. Ye M, Du YL, Nie YQ, Zhou ZW, Cao J, Li YF: Overexpression of activated leukocyte cell adhesion molecule in gastric cancer is associated with advanced stages and poor prognosis and miR-9 deregulation. Mol Med Rep 2015, 11:2004-2012

20. Weichert W, Knosel T, Bellach J, Dietel M, Kristiansen G: ALCAM/CD166 is overexpressed in colorectal carcinoma and correlates with shortened patient survival. J Clin Pathol 2004, 57: $1160-1164$

21. Hansen AG, Freeman TJ, Arnold SA, Starchenko A, Jones-Paris CR, Gilger MA, Washington MK, Fan KH, Shyr Y, Beauchamp RD, Zijlstra A: Elevated ALCAM shedding in colorectal cancer correlates with poor patient outcome. Cancer Res 2013, 73:2955-2964

22. Kahlert C, Weber H, Mogler C, Bergmann F, Schirmacher P, Kenngott HG, Matterne U, Mollberg N, Rahbari NN, Hinz U, Koch M, Aigner M, Weitz J: Increased expression of ALCAM/CD166 in pancreatic cancer is an independent prognostic marker for poor survival and early tumour relapse. Br J Cancer 2009, 101:457-464

23. Hansen AG, Arnold SA, Jiang M, Palmer TD, Ketova T, Merkel A, Pickup M, Samaras S, Shyr Y, Moses HL, Hayward SW, Sterling JA, Zijlstra A: ALCAM/CD166 is a TGF-beta-responsive marker and functional regulator of prostate cancer metastasis to bone. Cancer Res 2014, 74:1404-1415

24. Kristiansen G, Pilarsky C, Wissmann C, Kaiser S, Bruemmendorf T, Roepcke S, Dahl E, Hinzmann B, Specht T, Pervan J, Stephan C, Loening S, Dietel M, Rosenthal A: Expression profiling of microdissected matched prostate cancer samples reveals CD166/MEMD and CD24 as new prognostic markers for patient survival. J Pathol 2005, 205:359-376

25. van Kempen LC, van den Oord JJ, van Muijen GN, Weidle UH, Bloemers HP, Swart GW: Activated leukocyte cell adhesion molecule/CD166, a marker of tumor progression in primary malignant melanoma of the skin. Am J Pathol 2000, 156:769-774

26. Degen WG, van Kempen LC, Gijzen EG, van Groningen JJ, van Kooyk Y, Bloemers HP, Swart GW: MEMD, a new cell adhesion molecule in metastasizing human melanoma cell lines, is identical to ALCAM (activated leukocyte cell adhesion molecule). Am J Pathol 1998, 152:805-813

27. Donizy P, Zietek M, Halon A, Leskiewicz M, Kozyra C, Matkowski R: Prognostic significance of ALCAM (CD166/MEMD) expression in cutaneous melanoma patients. Diagn Pathol 2015, 10:86

28. Balkwill FR, Capasso M, Hagemann T: The tumor microenvironment at a glance. J Cell Sci 2012, 125:5591-5596

29. Whiteside TL: The tumor microenvironment and its role in promoting tumor growth. Oncogene 2008, 27:5904-5912

30. Zhang J, Liu J: Tumor stroma as targets for cancer therapy. Pharmacol Ther 2013, 137:200-215

31. Corbett TH, Griswold DP Jr, Roberts BJ, Peckham JC, Schabel FM Jr: Tumor induction relationships in development of transplantable cancers of the colon in mice for chemotherapy assays, with a note on carcinogen structure. Cancer Res 1975, 35:2434-2439 
32. Hoos A, Protsyuk D, Borsig L: Metastatic growth progression caused by PSGL-1-mediated recruitment of monocytes to metastatic sites. Cancer Res 2014, 74:695-704

33. Wolf MJ, Hoos A, Bauer J, Boettcher S, Knust M, Weber A, Simonavicius N, Schneider C, Lang M, Sturzl M, Croner RS, Konrad A, Manz MG, Moch H, Aguzzi A, van Loo G, Pasparakis M, Prinz M, Borsig L, Heikenwalder M: Endothelial CCR2 signaling induced by colon carcinoma cells enables extravasation via the JAK2Stat5 and p38MAPK pathway. Cancer Cell 2012, 22:91-105

34. Arbiser JL, Moses MA, Fernandez CA, Ghiso N, Cao Y, Klauber N, Frank D, Brownlee M, Flynn E, Parangi S, Byers HR, Folkman J: Oncogenic H-ras stimulates tumor angiogenesis by two distinct pathways. Proc Natl Acad Sci U S A 1997, 94:861-866

35. Schindelin J, Arganda-Carreras I, Frise E, Kaynig V, Longair M, Pietzsch T, Preibisch S, Rueden C, Saalfeld S, Schmid B, Tinevez JY, White DJ, Hartenstein V, Eliceiri K, Tomancak P, Cardona A: Fiji: an open-source platform for biological-image analysis. Nat Methods 2012, 9:676-682

36. Morikawa S, Baluk P, Kaidoh T, Haskell A, Jain RK, McDonald DM: Abnormalities in pericytes on blood vessels and endothelial sprouts in tumors. Am J Pathol 2002, 160:985-1000

37. Ozerdem U, Grako KA, Dahlin-Huppe K, Monosov E, Stallcup WB: NG2 proteoglycan is expressed exclusively by mural cells during vascular morphogenesis. Dev Dyn 2001, 222:218-227

38. Stein M, Keshav S, Harris N, Gordon S: Interleukin 4 potently enhances murine macrophage mannose receptor activity: a marker of alternative immunologic macrophage activation. J Exp Med 1992, 176:287-292

39. Chambers SE, O'Neill CL, O'Doherty TM, Medina RJ, Stitt AW: The role of immune-related myeloid cells in angiogenesis. Immunobiology 2013, 218:1370-1375

40. Jannie KM, Stipp CS, Weiner JA: ALCAM regulates motility, invasiveness, and adherens junction formation in uveal melanoma cells. PLoS One 2012, 7:e39330
41. Ishiguro F, Murakami H, Mizuno T, Fujii M, Kondo Y, Usami N, Yokoi K, Osada H, Sekido Y: Activated leukocyte cell-adhesion molecule (ALCAM) promotes malignant phenotypes of malignant mesothelioma. J Thorac Oncol 2012, 7:890-899

42. Lunter PC, van Kilsdonk JW, van Beek H, Cornelissen IM, Bergers M, Willems PH, van Muijen GN, Swart GW: Activated leukocyte cell adhesion molecule (ALCAM/CD166/MEMD), a novel actor in invasive growth, controls matrix metalloproteinase activity. Cancer Res 2005, 65:8801-8808

43. Hanahan D, Weinberg RA: Hallmarks of cancer: the next generation. Cell 2011, 144:646-674

44. Dippel V, Milde-Langosch K, Wicklein D, Schumacher U, Altevogt P, Oliveira-Ferrer L, Janicke F, Schroder C: Influence of L1CAM expression of breast cancer cells on adhesion to endothelial cells. J Cancer Res Clin Oncol 2013, 139:107-121

45. Zhao L, Lim SY, Gordon-Weeks AN, Tapmeier TT, Im JH, Cao Y, Beech J, Allen D, Smart S, Muschel RJ: Recruitment of a myeloid cell subset (CD11b/Gr1 mid) via CCL2/CCR2 promotes the development of colorectal cancer liver metastasis. Hepatology 2013, 57: 829-839

46. Cassetta L, Pollard JW: Cancer immunosurveillance: role of patrolling monocytes. Cell Res 2016, 26:3-4

47. Qian B, Deng Y, Im JH, Muschel RJ, Zou Y, Li J, Lang RA, Pollard JW: A distinct macrophage population mediates metastatic breast cancer cell extravasation, establishment and growth. PLoS One 2009, 4:e6562

48. Morvan MG, Lanier LL: NK cells and cancer: you can teach innate cells new tricks. Nat Rev Cancer 2016, 16:7-19

49. Coffelt SB, Wellenstein MD, de Visser KE: Neutrophils in cancer: neutral no more. Nat Rev Cancer 2016, 16:431-446

50. Hassan NJ, Simmonds SJ, Clarkson NG, Hanrahan S, Puklavec MJ, Bomb M, Barclay AN, Brown MH: CD6 regulates T-cell responses through activation-dependent recruitment of the positive regulator SLP-76. Mol Cell Biol 2006, 26:6727-6738 